\title{
Evening Exercise to Prevent Central Adiposity and Cardiometabolic Diseases
}

Policy Article

Akbar Nikkhah

Chief Highly Distinguished Professor, Department of Animal Sciences, Faculty of Agricultural Sciences, University of Zanjan, Foremost Principal Highly Distinguished Elite-Generating Scientist, National Elite Foundation, Iran.

\section{Abstract}

The objective of this article was to develop a global guideline based on the necessity of evening exercise to improve insulin turnover and intermediary metabolism. Glucose intolerance develops as day leaves for evening and night. Designing public health programs that involve evening and early night exercise can induce insulin sensitivity and reduce cellular irresponsiveness to insulin, especially in overweight and obese people. This is a feasible approach to help overcome the many health issues caused or augmented by obesity and diabetes mellitus.

Keywords: Evening; Exercise; Insulin; Glucose Tolerance; Public Health.

\section{*Corresponding Author:}

Akbar Nikkhah,

Chief Highly Distinguished Professor, Department of Animal Sciences Faculty of Agricultural Sciences, University of Zanjan, Foremost Principal Highly Distinguished Elite-Generating Scientist, National Elite Foundation, Iran.

Tel: 0098-241-5152801

E-mail: anikkha@yahoo.com

Received: June 17, 2015

Accepted: July 13, 2015

Published: July 15, 2015

Citation: Akbar Nikkhah (2015) Evening Exercise to Prevent Central Adiposity and Cardiometabolic Diseases. Int J Diabetol Vasc Dis Res, 3(6) 113-114. doi: http://dx.doi.org/10.19070/2328-353X-1500023

Copyright: Akbar Nikkhah ${ }^{\circ}$ 2015. This is an open-access article distributed under the terms of the Creative Commons Attribution License, which permits unrestricted use, distribution and reproduction in any medium, provided the original author and source are credited.

\section{Innovative Formulation and Discussion}

The global human populations increasingly suffer from obesity as a super-cancer of the modern age [1-4]. Public data suggest that in many parts of the world, obesity and overweightness occur in up to $60-70 \%$ of the entire populations. This is just overwhelmingly catastrophic and must be minimized to better life quality globally. Childhood obesity is also a rising concern, jeopardizing future adult health and life satisfaction. Obesity is usually linked to many health problems of notably diabetes, metabolic syndrome, fatty liver, hepatic steatosis and various cancers $[5,6]$.

Glucose intolerance and insulin resistance develop as evening and night begin [7]. This circadian phenomenon stems from the evolution of the mankind in nature where day and night are respectively the most and least active phases of the 24 -h period. When rested or asleep, much less nutrients are needed by human cells, and thus, much less insulin and related endocrinological work are required to maintain metabolic homeostasis. Due to such an evolutionary circadian property of human metabolism, taking evening and night food meals has been greatly discouraged to help prevent obesity and to reduce its severity in obese people [8-11]. Fitting circadian rhythms of exercise with those of eating has also been recently urged to improve intermediary metabolism and more effectively minimize risks from extreme central adiposity and diabetes $[5,6]$. Based on the major philosophy of the current article, evening and early night exercise can complement the success of the eating programs involving no major night meals and frequent but small day-time and early evening meals.

Adequately intense evening exercise that causes serious sweating and increased heart beating, will effectively improve cellular oxidation and waste management. As a result of the increased cellular demands for oxidation and energy, circulating nutrients can more easily enter cells mostly due to the already enhanced insulin-driven uptake. Owing to the improved insulin turnover, less insulin would be required to metabolize substrates, when compared to a scenario of no or little evening exercise. Thus, diabetic conditions are least likely to happen. Intense exercise is expected to induce hunger. Eating limited amount of food in certainly needed, whereas it would be extra and entirely unhealthy without the evening exercise. The latter often occurs in today's lifestyles. However, care must be taken to not overconsume energy after evening exercise to greatly benefit from the metabolic advantages. An example for minimal equivalent intensity of the evening exercise recommended herein would be approximately 20-30 min of mid-speed running of $5-10 \mathrm{~km} / \mathrm{h}$.

\section{Implications}

This pragmatic public health article developed a global strategic guideline for the highly demanded evening exercise. This public health program greatly helps to improve intermediary metabolism and insulin action, particularly in overweight and obese individu- 
als. The strategy has an immense capacity to prevent obesity and related cardiovascular and metabolic abnormalities.

\section{Acknowledgements}

Iran's Ministry of Science Research and Technology, National Elite Foundation, and University of Zanjan are thankfully acknowledged for supporting the author's global programs of optimizing science edification in the new millennium.

\section{References}

[1]. Nikkhah A (2012) Eating time modulations of physiology and health: life lessons from human and ruminant models. Iran J Basic Med Sci 15(4): 891899.

[2]. Nikkhah A (2012) Time of Feeding an Evolutionary Science. Lap Lambert Academic Publishing, Germany. 92.

[3]. Nikkhah A (2015) Secure Weight Management via Fitting Circadian Pat- terns of Physical Activity, Resting and Eating. Adv Obes Weight Manag Cont 2(4): 23 .

[4]. Nikkhah A (2015) Effective Weight Management in Periparturient Women through Optimizing Eating Timing: A Novel Global Approach. Adv Obes Weight Manag Control 2(3): 18.

[5]. Nikkhah A (2015) Circadian Fitting of Exercise and Eating Patterns: The Secret of Healthy Life. J Bioprocess Biotech 5: e129.

[6]. Nikkhah A (2015) Harmonizing Eating and Exercise Circadian Rhythms for Optimal Glucose-Insulin and Vascular Physiology. Int J Diabetol Vasc Dis Res 3(3): 87-88.

[7]. la Fleur SE, Kalsbeek A, Wortel J, Fekkes ML, Buijs RM (2001) A daily rhythm in glucose tolerance: a role for the suprachiasmatic nucleus. Diabetes 50(6): 1237-1243

[8]. Nikkhah A (2015) Discovering the Right Time to Take Food to Smash Diabetes. J Diabetes Res Ther 1.1.

[9]. Nikkhah A (2015) Avoid Large Night Meals to Stay Fit. J Obes Weight Loss Ther 4: e115. http://dx.doi.org/10.4172/2165-7904.1000e115.

[10]. Nikkhah A (2014) When to Eat to Beat Obesity and Diabetes? J Diabetes Metab 5: 7. http://dx.doi.org/10.4172/2155-6156.1000e115.

[11]. Nikkhah A (2014) Timing of Eating to Eradicate Diabetes: A Feasible Prescription. J Diabetes Metab 5: 8. 